\title{
Effects of Tube Depth and Infusion Rate of Continuous Humidification by Endotracheal Intubation on Humidification Effect
}

\author{
Hui Sun, Dan Li, Wan Luo, Lin Feng \\ Ward 2, Department of Stomatology, PLA General Hospital, China \\ Email: 1838716933@qq.com
}

How to cite this paper: Sun, H., Li, D., Luo, W. and Feng, L. (2017) Effects of Tube Depth and Infusion Rate of Continuous Humidification by Endotracheal Intubation on Humidification Effect. Open Journal of Nursing, 7, 123-127.

http://dx.doi.org/10.4236/ojn.2017.71011

Received: August 19, 2016

Accepted: January 22, 2017

Published: January 25, 2017

Copyright ( 92017 by authors and Scientific Research Publishing Inc. This work is licensed under the Creative Commons Attribution International License (CC BY 4.0). http://creativecommons.org/licenses/by/4.0/

\begin{abstract}
Objective: To investigate the continuous humidification tube insertion depth of endotracheal intubation and the flow rate of the wetting effect. Methods: From October 2008 to May 2010, among 132 patients of oral and maxillofacial surgery with tracheal intubation, continuous infusion can be adjusted to the wet method; according to the wet pipe, insertion depth of the flow rate is divided into four groups, by four different depths and velocities of the wetting effect, to be analyzed. Results: B group was significantly lower than other groups satisfied with indicators of four significantly different effects of humidification. Conclusion: When continuous humidification tube insertion depth of endotracheal intubation is $10-12 \mathrm{~cm}$, and flow rate is $15-20 \mathrm{ml} / \mathrm{h}$, the wetting effect will achieve greater satisfaction.
\end{abstract}

\section{Keywords}

Intubation, Continuous Humidification, Tube Depth, Infusion Rate, Humidification Effect

\section{Introduction}

Due to the characteristic surgical site and postoperative bleeding, endotracheal tube is placed into many patients after oral maxillofacial surgery [1]. However, after endotracheal intubation, the upper respiratory tract loses its heating and humidifying effects on the inhaled air. As a result, the humidified dry air directly enters the lower respiratory tract, forming sputum scab in the endotracheal tube or the upper respiratory tract, thereby leading to airway blockage, if the humidification of airway is not sufficiently performed in clinical nursing [2]. Therefore, reasonable and effective airway humidification is especially important to patients with endotracheal intubation. After implementing various kinds of humidifica- 
tion methods, such as wet gauze covering, intratracheal infusion, ultrasonic aerosol inhalation, artificial nose, and continuous infusion airway humidification, continuous infusion airway humidification controlled by adjustable infusion has been adopted since 2008 [3]. Compared with the conventional one, this method can infuse the humidification liquid into the respiratory tract in a stable, constant, slow and continuous way, so as to achieve effective humidification. However, in clinical practice, it is found that the insertion depth into the endotracheal tube and the infusion rate of the humidifying tube directly affect the humidification effect, but there is no uniform standard in the relevant literature. In particular, some reports recommended a tube depth of about $15-18 \mathrm{~cm}$ and an infusion rate of about $8-10 \mathrm{ml} / \mathrm{h}$. For this purpose, this paper investigated the specific tube depth and infusion rate that enabled the optimal humidification effect through clinical observation.

\section{Objects and Methods}

\subsection{Objects}

One hundred and thirty-two patients were selected from October 2008 to May 2010 to undergo endotracheal intubation in our department. There were 87 males and 46 females, aged 14 - 76 years old, with an average of 43 years old. All of them were patients who underwent endotracheal intubation after oral maxillofacial surgeries, including 37 orthognathic surgeries, 28 mandibular fracture reduction surgeries, 51 surgeries for benign and malignant tumors, and 16 cases of uvulopalatopharyngoplasty (Table 1). Their conditions were stable after surgery, and all of them were conscious adult patients with cough reflex. Low-flow oxygen was given without using the ventilator, with an average intubation time of 15 20 hours, a length of endotracheal tube of $30 \pm 2 \mathrm{~cm}$, and a lumen diameter of $7-8$ $\mathrm{mm}$.

\subsection{Methods}

One hundred and thirty-two patients were randomly divided into 4 groups according to the sequence of surgery, with 33 patients in each group. The flexible hose for removing the scalp vein catheter of the adjustable infusion set was inserted into the inner wall of the endotracheal tube. In Group A, tube depth was $10-12 \mathrm{~cm}$, and infusion rate was $8-10 \mathrm{ml} / \mathrm{h}$; in Group B, tube depth was 10 $12 \mathrm{~cm}$, and infusion rate was $15-20 \mathrm{ml} / \mathrm{h}$; in Group C, tube depth was $15-18$ $\mathrm{cm}$, and infusion rate was $8-10 \mathrm{ml} / \mathrm{h}$; in Group D, tube depth was $15-18 \mathrm{~cm}$,

Table 1. Sociodemographic and clinical characteristics.

\begin{tabular}{ccccc}
\hline & Youngs & Middles & Olds & Total \\
\hline TUMOR & 1 & 3 & 7 & $11(30 \%)$ \\
TRAUMA & 2 & 1 & 0 & $3(10 \%)$ \\
INFECTION & 1 & 3 & 3 & $7(20 \%)$ \\
DEFORMITY & 3 & 2 & 1 & $6(20 \%)$ \\
\hline
\end{tabular}


and infusion rate was $15-20 \mathrm{ml} / \mathrm{h}$. We also found in past experience that when the humidification tube was fixed inside the endotracheal tube, sputum scab might be easily formed on the side not infiltrated by the humidification liquid due to limitations of the position. For this reason, an approach simultaneously fixing the humidification tube and the oxygen tube inside the intubation tube was adopted for each group, keeping the lower end of the humidification tube 1 - 2 $\mathrm{cm}$ below the lower end of the oxygen tube. Therefore, humidification liquid could be evenly distributed in the area to be humidified after being blown by oxygen, making the humidification effect more uniform.

\subsection{Selection of Humidification Liquid}

The humidification liquid was selected as $500 \mathrm{ml}$ of sterile water for injection +5 $\mathrm{mg}$ of dexamethasone $+100 \mathrm{mg}$ of etimicin sulfate $+30 \mathrm{mg}$ of mucosolvan.

\section{Humidification Effect and Criteria}

The humidification effect was determined according to the patient's subjective symptoms and the changes in some monitored indicators. The subjective symptoms include suffocation, choking and emotions, while the changes in monitored indicators include sputum viscosity, auscultation, and sputum attached to the wall of endotracheal tube. On this basis, the humidification effects were divided into two standards.

\subsection{Satisfaction}

Thin sputum can be smoothly sucked out or coughed up. No dry rales or a lot of wheezy phlegm can be auscultated in the trachea. The patient is quiet with smooth breathing. The removed endotracheal tube wall is clear and free of mucus.

\subsection{Dissatisfaction}

Sticky sputum is not easy to be sucked out. Dry rales can be auscultated in the trachea; too thin sputum that should be constantly drawn. A lot of wheezy phlegm can be auscultated in the trachea. The patient suffers frequent cough; unstable emotion, anxiety, and intolerance to the tube. The removed endotracheal tube wall is attached with sputum.

\section{Results}

The sputum properties, cough symptoms, emotional expression, and dissatisfaction rate of humidification effect, as well as the sputum attached to the removed endotracheal tube wall and its attachment site, are compared as shown in the table below. According to the table (Table 2), the dissatisfaction rate of Group B was significantly lower than the other groups; there was significant difference in the humidification effect between the four groups. It was concluded that, when the endotracheal intubation continuous humidification tube's depth was $10-12$ $\mathrm{cm}$ and its infusion rate was $15-20 \mathrm{ml} / \mathrm{h}$ (Group B), the humidification effect 
was more satisfying (Table 3).

\section{Discussion}

Airway humidification is particularly important for the maintenance of the normal function of the respiratory tract and the prevention of various complications. The humidification of artificial airway has been extensively reported in previous studies. At present, a variety of humidification methods are put into clinical use, with respective advantages and disadvantages [4]. In comparison, continuous airway humidification delivers a positive and clear effect. However, there is no uniform standard on how to choose the tube depth and infusion rate of endotracheal intubation continuous humidification tube, in order to achieve better humidification effect. This study was intended to analyze the results of four classified groups, in an attempt to prove some reference to the clinical work. In Groups A and C, for instance, most patients were found with viscous sputum. The reason for this was that the humidification liquid could not provide an effective humidification when passing through the wall, because of its low flow rate $(8-10 \mathrm{ml} / \mathrm{h})$, about 2 drops per minute, combined with airflow effects of breathing, coughing, and oxygen uptaking. As a result, a total of 15 cases of viscous sputum were found in the two groups, and the sputum attached to the removed endotracheal tube wall was mostly in the lower part of the intubation tube, indicating a too low flow that might be exhausted by physical actions before reaching the lower end of the endotracheal tube. In Group D, a lot of cases were found with too thin sputum and frequent cough, and the humidification tube's depth was $15-18 \mathrm{~cm}$ and infusion rate was $15-20 \mathrm{ml} / \mathrm{h}$. Given the certain arc of the endotracheal tube making it impossible for the humidification

Table 2. Sputum properties, cough symptoms, emotional expression, and dissatisfaction rate of humidification effect in the four groups.

\begin{tabular}{ccccccc}
\hline Groups & $\begin{array}{c}\text { Viscous } \\
\text { sputum }\end{array}$ & $\begin{array}{c}\text { Thin } \\
\text { sputum }\end{array}$ & $\begin{array}{c}\text { Dry rales } \\
\text { rate }\end{array}$ & $\begin{array}{c}\text { Frequent } \\
\text { cough }\end{array}$ & Anxiety & Dissatisfaction \\
\hline Group A & 9 & 0 & 3 & 1 & 2 & $45.4 \%$ \\
Group B & 2 & 1 & 0 & 0 & 1 & $12.4 \%$ \\
Group C & 6 & 0 & 1 & 2 & 2 & $33.6 \%$ \\
Group D & 2 & 4 & 0 & 3 & 3 & $33.2 \%$ \\
\hline
\end{tabular}

Table 3. Sputum attached to the removed endotracheal tube wall and its attachment site in the four groups.

\begin{tabular}{cccc}
\hline Groups & Middle wall & Lower wall & Total \\
\hline Group A & 3 & 8 & $11(3 \%)$ \\
Group B & 1 & 2 & $3(9 \%)$ \\
Group C & 2 & 5 & $7(21 \%)$ \\
Group D & 4 & 2 & $6(18 \%)$ \\
\hline
\end{tabular}


tube to closely attach to the wall, the humidification droplets with relatively faster infusion rate might directly enter the trachea, irritating the respiratory tract to cause cough, or even severe coughing, ultimately leading to the patient's anxiety and intolerance to the tube; moreover, some patients might cough up the dropped humidification liquid, due to the irritating cough, which could also affect the humidification effect. The tube depth was tested after the intubation tube was removed, and it was found that part of the humidification tube was indeed unable to closely attach to the wall. In addition, the sputum attached to the removed endotracheal tube wall was mostly in the middle part of intubation tube, suggesting that the sputum coughed up to the tube wall was higher than the lower end of the humidification tube and thus failed to be well humidified.

\section{Conclusion}

In summary, through comparison and analysis of the results, it was found that when the endotracheal intubation continuous humidification tube's depth was $10-12 \mathrm{~cm}$ and infusion rate was $15-20 \mathrm{ml} / \mathrm{h}$, the humidification effect was more satisfying. During the maintenance of artificial airway, it is essential to take effective measures to conduct airway humidification in a targeted way and to ensure smooth drainage of secretions, so as to achieve the optimal humidifying effects, maintain the normal functions of the respiratory tract, and lay a good foundation for the early recovery of the patients.

\section{References}

[1] Wang, D.-L., Ye, H.-H. and Lv, W.-B. (1995) Airway Built-In Tube Injection Medicine Best Place and Position of Experimental Research. Chinese Journal of Nursing, 30, 351-352.

[2] Chen, J. and Qu, D.-M. (2007) Airway Management of Patients with Mechanical Ventilation. Jilin Medical Journal, 28, 978.

[3] Chen, F. and Zhang, S.-Z. (2002) Two-Channel Trace Pump Application of Wetting Airway after Tracheotomy. The Journal of Nursing Research, 16, 79.

[4] Pan, M.-F. (2004) The Research Progress of Artificial Airway of Wetting. The Journal of Nursing Research, 18, 668-669. 
Submit or recommend next manuscript to SCIRP and we will provide best service for you:

Accepting pre-submission inquiries through Email, Facebook, LinkedIn, Twitter, etc. A wide selection of journals (inclusive of 9 subjects, more than 200 journals)

Providing 24-hour high-quality service

User-friendly online submission system

Fair and swift peer-review system

Efficient typesetting and proofreading procedure

Display of the result of downloads and visits, as well as the number of cited articles Maximum dissemination of your research work

Submit your manuscript at: http://papersubmission.scirp.org/

Or contact ojn@scirp.org 